\title{
Sound to electric energy generating device
}

\author{
Maricel G. Dayaday, Jordan-James S. Olivo \\ Department of Electronics Engineering, College of Engineering and Information Technology, \\ University of Southern Mindanao, Kabacan, Philippines
}

\begin{tabular}{l}
\hline \hline Article Info \\
\hline Article history: \\
Received Jan 14, 2021 \\
Revised Apr 27, 2021 \\
Accepted May 1, 2021 \\
\hline
\end{tabular}

Keywords:

Electric energy generating device Electromagnetic transducer Linear regression

Sound

Subwoofer speaker

\begin{abstract}
This paper presents the potential of an electromagnetic transducer device in a form of audio speaker that is used to capture sound waves to be converted into electricity. It is an interesting concept but less explored by researchers. The objective of the study is to measure the potential of electromagnetic transducer as a way to generate electricity. It deals with the creation of electricity through movement and magnetism. Sound waves can induce movement on the surface which in turn moves the transducer thus creating electricity. The source of sound was coming from an 8-inch subwoofer speaker with a frequency of $80 \mathrm{~Hz}$ that was held constant throughout the experiment. Furthermore, using simple linear regression analysis, the study showed that for every linear increase of sound intensity level and distance of the source, there is an exponential increase and an exponential decrease in the voltage root mean square (RMS) respectively. The functionality assessment of the device was statistically analyzed using completely randomized design. It was found that the energy level significantly increased as the sound intensity level increases given a fixed distance of $15 \mathrm{~mm}$ from the source. The device could generate enough energy to power small electronics such as light emitting diodes (LED), transistor and resistor.
\end{abstract}

This is an open access article under the CC BY-SA license.

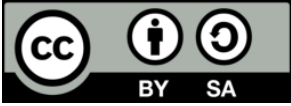

\section{Corresponding Author:}

Maricel G. Dayaday

Department of Electronics Engineering

College of Engineering and Information Technology

University of Southern Mindanao, Kabacan, 9407, Philippines

Email: mgdayaday@usm.edu.ph

\section{INTRODUCTION}

Electricity plays a vital role in the society. Without electricity, life will be very uneasy because all of the technologies that assist in daily life need electricity to operate. As the world population rapidly increases, the demand of electricity also increases. However, electric power production is very limited. Studies show that majority of the world's power relies upon the utilization of fossil fuels. An alternative source of electric energy is sound energy which has vast possibilities that have been left unexploited as one of the alternative and sustainable sources of electricity.

Utilizing sound as a source of energy to deliver a feasible source of electricity is a step forward in this direction, hence the study sound to electric energy generating device. The purpose of the study is to explore the possibility of generating electrical potential from constant high-intensity sound. The [1], [2] source of loud noises can be found in many places and devices such as disco machines, karaoke, construction areas, factories, concerts, clubs, busy streets, airport railways and loudspeakers. The developed technique that produces electrical energy through sound energy helps in reducing pollution [3]. In addition, it helps to reduce the power consumption in many households thus, reducing the burden of paying electric bills by simply putting the device directly to the loud places and allows it to absorb the sound waves from the surroundings. 
Whenever there is a power outage, the device can be useful to act as an emergency source. Therefore, the electric energy production from the accessible sound source can prove to be relevant and meaningful.

Generally, the study sought to design an alternative and sustainable source of energy and to determine the extent of usefulness of the device. Specifically, to develop an electromagnetic device that can utilize sound energy to convert it to electric energy. Furthermore, the study sought to present a model between the voltage root-mean-squared (RMS) across the coil and a model between the relationship of the distance of the sources from the device and induced voltage RMS.

The first conceptualization of electromagnetic induction by Michael Faraday that electromotive force can be obtained in two methods: firstly, is when electric conductor is constantly moving within a static magnetic field and when the electric conductor is kept in a moving magnetic field. Faraday realized that the electromagnetic induction influenced by the strength of the magnet, the number of coils, and the speed of relative motion between coil and magnet. Hence, when the number of turns of wire, strength and area of the magnet, and the speed of relative motion between coil and magnet are high, this will produce to more induced emf or voltage [4].

Moreover, in Faraday's [5] first experimental demonstration showed that when current started to flow in one wire, a sort of wave would travel through the ring and cause some electrical effect on the opposite side, connected with one wire into a galvanometer, wire to a battery and a transient current was observed. This induction was due to the change in magnetic flux that occurred when the battery was connected and disconnected. Electromagnetic transducer is a type of transducer which uses the principle of electromagnetic induction. This kind of transducer can be found in many devices such as speakers and microphones. In the experiment [6]-[9], they proposed a technique by using electromagnetic transducers cause by the sound pressure waves to produced vibrations and converted it into electrical energy. The circuit was connected at the sources of the noise: 1 meter from the car horn and 1 meter from the motorbike silencer. In that the connection, the sound waves produced drop on a diaphragm, which is coupled to an induction coil placed in front of a permanent magnet. As the sound waves reach the diaphragm vibrates, the coil moves along with it. Using digital multimeter in volts (V) to measure the voltage drop across the coil, sound was measured though a sound meter in decibel $(\mathrm{dB})$ located close to the source. A transformer was used to step up the voltage produced across the coil. The results of their experiment were conclusive. For car horn, at $87 \mathrm{~dB}$, the produced voltage across the coil is about $0.6 \mathrm{~V}$, and at $90 \mathrm{~dB}$, the produced voltage is about $1.2 \mathrm{~V}$ to $1.62 \mathrm{~V}$. For motorbike silencer, at $103 \mathrm{~dB}$, the voltage produced across the coil is about $0.5 \mathrm{~V}$, and at $114 \mathrm{~dB}$, the produced voltage is about $2.7 \mathrm{~V}$. The results showed further that the equivalent voltage which was measured at the multimeter increased when the noise level increases. Furthermore, the sound energy and the produced voltage are non-linear in relation as shown in Figures 1 (a) and (b).

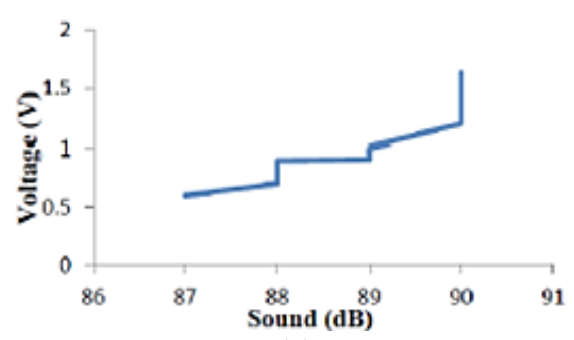

(a)

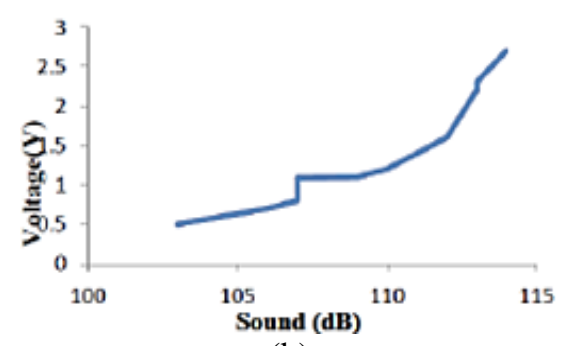

(b)

Figure 1. Sound energy and the produced voltage are non-linear in relation:

(a) car horn and (b) motorbike silencer [6]

While, Bhatnagar [10] proposed three methods in transforming sound energy to electric energy. The first method involves placing a very thin curtain-like diaphragm that will be fluctuated through pressure by the sound wave. A coil is attached to it and then placed between permanent magnets. Constant fluctuation in the curtain will result to movement in the coil affecting the magnetic field of the magnets that will produce motional emf and will generate voltage across it. As per Faraday's law is given by:

$$
E=N(A \Delta B) / \Delta t
$$

where:

$E=$ Generated $E M F$ or voltage

$\Delta B / \Delta t=$ rate of relative motion 
$N=$ number of windings of wire coil

$\mathrm{A}=$ area of the magnet.

So, the sound wave that produces oscillation could be converted into electricity [11]-[15]. But its drawback is that efficiency will only be reach when it places to high decibel of sound such as nuclear power plant and other industries with huge and noisy machines. Rediscovered [16] that electricity can form among two dissimilar conductors, at the heat of the thermoelectric effect is that a temperature incline in a conducting material results in heat flow; this results in the dispersion of charge carriers. In turn the flow of charge carriers between the hot and cold regions creates a potential difference.

The second method is by converting sound energy into heat energy. The sound energy [10], [17] that travels will interrupt the particle of the medium and these interruptions created by sound will be used to change it into heat energy. The method is less efficient as more energy losses will occur during conversion of sound energy to heat energy.

The third technique is by transforming sound energy to electrical energy by piezoelectric material. The polarity of the electric charge is reversed which happened when the direction of the strain reverses. These instances [10] occur on certain single crystal materials such as when it is deformed by the application of peripheral stress which makes electric charges to appear on the crystal surfaces. This is called the direct piezoelectric effect, and the crystals that exhibit it are classed as piezoelectric crystal. However, the use of piezoelectric materials is expensive and unpractical for the reasons of generation. In addition, [18] piezoelectric transducer is affected by temperature variations and relative humidity, it operates with small electric charge and it has low output so some external circuit is attached to it. [19]-[23] showed the distinction of piezoelectric used for sound wave energy harvester. To make it comparable to that of environmental human sound which is at 50-100 dB, the experiment was set at range of 35-100 dB. So as to achieve an improved output power, the energy transducer utilized in the experiment was Piezoelectric type Q220-A4-503 YB.

Three different types of harnessing circuitry such as full-wave rectifier, Gillard voltage, and Dickson voltage multiplier were utilized to the output of piezoelectric transducer with corresponding values shown in Figures 2 (a) and (b). A good agreement with expected theory within the frequency of interest was attained as measured in the results of piezoelectric transducer with and without connected to external circuitry devices. Maximum power response of performance was achieved with $2057.2 \mathrm{uW}(33.133 \mathrm{dBuW})$ at $96 \mathrm{~dB}$. Among the three types of harnessing circuitry, Villar and Dickson voltage multipliers produced $9.817 \mathrm{~V}, 9.593 \mathrm{~V}$ respectively while full wave bridges produced $3.504 \mathrm{~V}$ at $96 \mathrm{~dB}$ sound intensity level. The finest performance was achieved when the piezoelectric transducer was connected to Villard voltage multiplier [16].

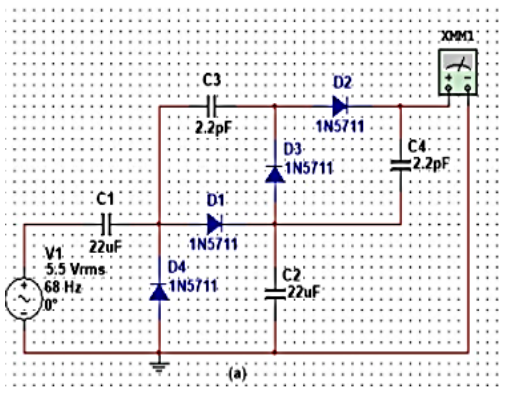

(a)

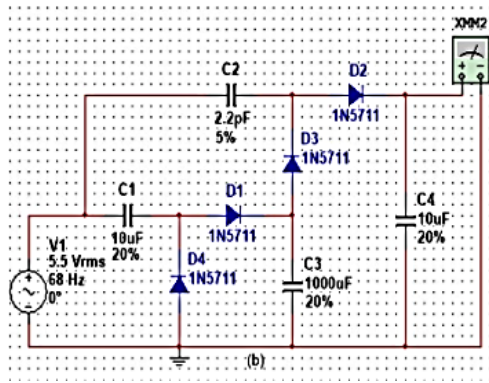

(b)

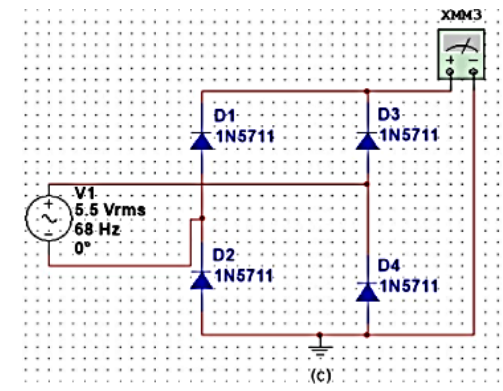

(c)

Figure 2. These figures are: (a) villard multiplier, (b) dickson multiplier, and (c) full-bridge rectifier

Farghaly et al. [23] proposed a study regarding the use of piezoelectricity to harness sound energy to change it to electrical energy. The researchers concluded that utilizing the noise to create electricity from the selected places using the concept of piezoelectricity is effective [24], [25]. The amount of electric energy produced was about 0.024 -watt hr. The energy produced is too small to be used in practical application. The researchers suggested that the area should be utilized to hundreds of square meters in order to harvest considerable amount of electric energy that can be used to power LED street lamp or it can be stored and used for any devices that need greater amount of electric energy when needed in applications, this would help in reducing power consumption.

After thorough investigation and comprehension in the related literature and studies that highlights the sound energy as a potential source of electric energy, the researchers wish more to extend the utilization of sound energy to produce electric energy by applying the concept of electromagnetic induction rather than piezoelectricity due to latter's impractical application and complex method in producing electricity. In addition, the researchers want to develop the device presented on this chapter in a relatively new concept of 
evaluating its functionality. Enhancing its capability by storing electric potential energy produced by the device, this will lead to more advanced mechanism of harnessing sound energy so that it can be more helpful in many practical applications in the world of electricity.

\section{RESEARCH METHOD}

Experimental method of research had been used in this study in finding out and in developing the device suitable for the users in creating a new source of electricity out of noise. This study was implemented using a thorough experimentation and replication method in making the design of circuitry and test the functionality of the device. The device generated energy by converting the vibration coming from the noise and magnetism to electrical energy. It is composed of a diaphragm, frame, voice coil and N52 grade neodymium magnet. The diaphragm of the device is served as the noise absorber, the diaphragm is about 8 inches long and is attached to the voice coil. The diaphragm is made of a light material so that it will be more sensitive to oscillation. The voice coil has a diameter of about 1.6 inches and is made up of 125 turns of \#32 AWG copper wire. The frame then supports the diaphragm. Three N52 grade neodymium magnets with 1.5" diameter and 0.5 " thickness is placed inside the voice coil in order to create the electromagnetic transducer and in which the both ends of the voice coil is attached to the circuit

Figure 3 (a) show the schematic and block diagram of the device, in which the circuit is composed of a step-up transformer, diodes, and capacitors. The step-up transformer has a primary-to-secondary turns ratio of about 1:50. Four 1N5822 diodes are used to rectify the input voltage and electrolytic capacitors will be used to filter the output voltage and for energy storage while Figure 3 (b) explains the flow of harnessing sound energy to produce electricity, in which the sound waves coming from the source were used to vibrate the diaphragm of the speaker, thus triggering the electromagnetic transducer. This resulted to induced voltage to be stepped-up by a transformer. The alternating current (AC) voltage was converted to direct current (DC) voltage using diode for rectification and capacitors for filter and energy storage. To measure the sound intensity level from the source, decibel meter was used. On the other hand, to measure the induced RMS voltage in the electromagnetic transducer, oscilloscope was used and digital multimeter for voltage output.

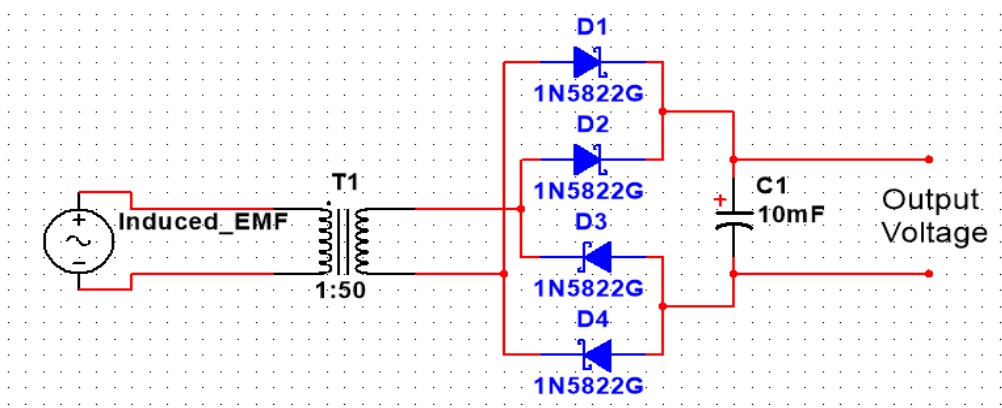

(a)

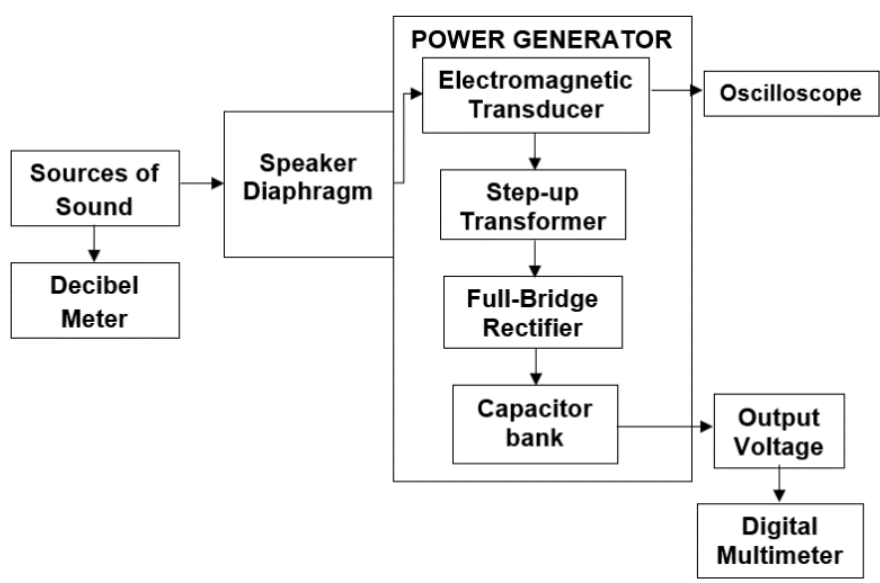

(b)

Figure 3. Schematic and block diagram of the device: (a) schematic and block diagram of the device and (b) explains the flow of harnessing sound energy to produce electricity 
The evaluation was done by using a loudspeaker that can handle around 150 watts. The speaker was an 8-inch sub-woofer so that it is capable of producing and handling very low frequencies. Frequency with $80 \mathrm{~Hz}$ was used throughout the study. To determine the relationship between the sound intensity level and the induced voltage RMS across the coil, 20 voltages RMS were induced across the coil for each random sound intensity level, with distance between the sound source and device held constant. To determine the relationship between the distance of the device from the sound source and the induced voltage RMS across the coil 48 voltages RMS were induced across the coil in 10 intervals beginning at $30 \mathrm{~mm}$ up to $500 \mathrm{~mm}$, with frequency and sound intensity level held constant. In both cases, there were 5 replications for the induced voltage RMS in each interval, and the data were based on the average of the five measurements. To determine the functionality, 4 output voltages were considered in determining the stored energy in a given amount of time for each corresponding sound intensity level using the formula. There were 3 replications of output voltages for each sound intensity level and the voltage output was determined from the average.

Regression models were used to determine the relationship between the induced voltage RMS and the sound intensity level, and the relationship between the induced voltage RMS and distance of the device from the source. For the functionality of the device, the data analysis and interpretation were done using completely randomized design with $1 \%$ level of significance.

\section{RESULTS AND DISCUSSION}

\subsection{Electromagnetic transducer device}

Figures 4 (a) and (b) show the developed device. The diaphragm of the device is made up of a light material in order to increase the sensitivity to the oscillation produced by the sound pressure waves from the source. The diaphragm is connected to the voice coil which is supported by a flexible material wrapping a strong permanent magnet in order to produce energy which will be used to power electronic components.

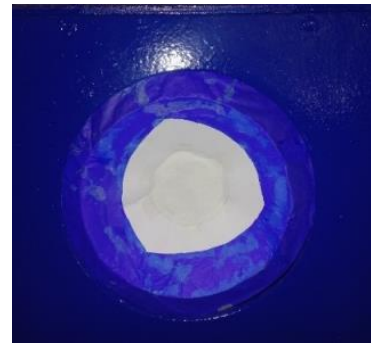

(a)

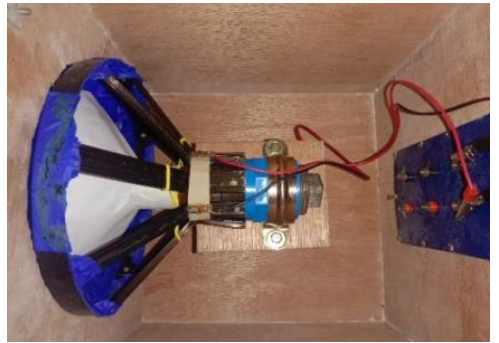

(b)

Figure 4. Developed device: (a) front view of the device and (b) top view of the device

\subsection{Regression model between the sound intensity level and voltage RMS}

There were about 20 data gathered during the experiment. The sound intensity level (x) came out as a predictor for voltage RMS (y) at a certain distance from the source. It shows that for every linear increase of sound intensity level resulted in an exponential increase of voltage RMS as shown in Figure 5 (a). Figure 5 (b) shows that there is a very potential strong linear relationship between two variables in the logarithmic values of the voltage RMS. This implies that the logarithmic equation can be used to better predict the induced voltage RMS at a given sound intensity level and due to a small standard error.

Table 1 further shows that the values: multiple R, R square, and standard error in logarithmic regression model that it is more reliable and preferable, and gives a better prediction in determining the voltage RMS value in a given sound intensity level compared to the linear regression model. This connotes that the linear equation is not applicable to predict the values of voltage RMS at a given sound intensity level and due to very high standard error. A logarithmic equation may provide a better fit, given that the decibel is in a logarithmic scale. As expected, greater air pressure waves will trigger the transducer as the sound intensity level increases. Further result indicates that more energy can be produced at very high decibels. Moreover, the relationship between the two variables is consistent with the research study of [5]. Also, Table 2 shows that the constant and the variable $\mathrm{x}$ are highly significant between linear and logarithmic.

The regression model for induced voltage RMS (Y) was computed to be: $\mathrm{Y}=10.863 \ln (\mathrm{x})-44.018$ where $\mathrm{x}$ is the sound intensity level in decibels $(\mathrm{dB})$ and $\mathrm{Y}$ is the logarithmic value of the induced voltage RMS (mV). Explicitly, at $85 \mathrm{~dB}$, a common sound intensity level at busy traffic in streets, the predicted induced voltage RMS will be equal to $69.58 \mathrm{mV}$, whereas from $100 \mathrm{~dB}$ to $120 \mathrm{~dB}$ which can be found in most 
of the industrial sites, loud concerts and airport railways, the induced voltage RMS will have a value of 406 $\mathrm{mV}$ up to $3 \mathrm{~V}$ from a certain distance. This signifies that considerable amount of energy can be produced to power up small electronics devices, insofar as sound intensity is consistently high.

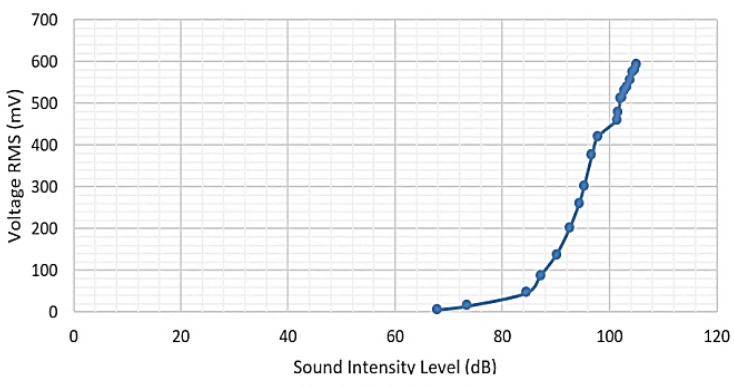

(a)

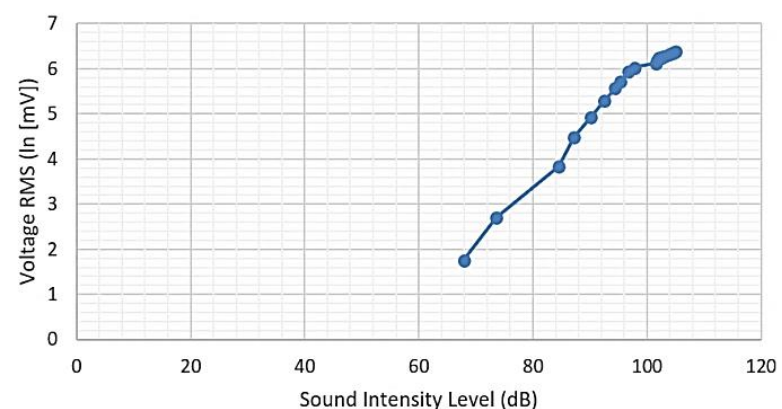

(b)

Figure 5. These figures are: (a) voltage RMS vs. sound intensity level plot and (b) voltage RMS vs. sound intensity level logarithmic plot

Table 1. Regression statistics between the sound intensity level and voltage RMS (linear and logarithmic)

\begin{tabular}{llll}
\hline \multicolumn{4}{c}{ Regression statistics } \\
\multicolumn{2}{c}{ Linear regression model } & \multicolumn{2}{l}{ Logarithmic regression model } \\
\hline Multiple R & 0.935022 & Multiple R & 0.98839829 \\
R Square & 0.874265 & R Square & 0.976931179 \\
Standard Error & 75.94372 & Standard Error & 0.204741752 \\
Observations & 20 & Observations & 20 \\
\hline
\end{tabular}

Table 2. Coefficients and significant value of variable $\mathrm{x}$ between the sound intensity level and voltage RMS (linear and logarithmic).

\begin{tabular}{lcclcc}
\hline \multirow{2}{*}{ Linear regression model } & \multicolumn{5}{c}{ Regression statistics } \\
& Coefficient & Sig & & Logarithmic regression model & Coefficient \\
\hline Constant & -1421.24 & $5.37 \mathrm{E}-08^{* * *}$ & Constant & -6.396444511 & $1.57 \mathrm{E}-11^{* *}$ \\
Sound Intensity Level (x) & 18.62474 & $1.55 \mathrm{E}-09^{* *}$ & Sound Intensity Level (x) & 0.123916759 & $13.47^{* *}$ \\
\hline ** Significant at 0.01 level Sig - significance (p-value) & &
\end{tabular}

\subsection{Regression model between the distance and voltage RMS}

There were about 48 data gathered during the experiment. The distance of the source (x) came out as a predictor for voltage RMS (y) at a certain sound intensity level of the source. It shows that for every linear increase of the distance of the source resulted in an exponential decrease of voltage RMS as shown in Figure 6 (a). Figure 6 (b) show that the two variables in the logarithmic values of the voltage RMS have very strong relationship. This implies that the logarithmic equation can be used to predict the induced voltage RMS at a given sound intensity level and due to a small standard error.

Table 3 further shows that the values: multiple R, R square, and standard error in logarithmic regression model that it is more reliable and preferable, and gives a better prediction in determining the voltage RMS value in a given distance from the source compared to the linear regression model. This connotes that the linear equation is not applicable to predict the values of voltage RMS at a given sound intensity level and due to very high standard error. As expected, the air pressure waves coming from the source greatly attenuates as it travels along with the distance. Further result indicates that very small energy can be produced if the device is distant from the source, but at very close distance, considerable amount of energy can be produced. Also, Table 4 shows that the constant and the variable $\mathrm{x}$ are highly significant between linear and logarithmic.

The regression model for induced voltage RMS (Y) was computed to be: $\mathrm{Y}=-1.946 \ln (\mathrm{x})+15.085$ where $\mathrm{x}$ is the distance of the source $(\mathrm{mm})$ and $\mathrm{Y}$ is the logarithmic value of the induced voltage RMS $(\mathrm{mV})$. Explicitly, at $50 \mathrm{~mm}$ from the source, the induced voltage RMS will be around at $1.8 \mathrm{~V}$, whereas half-meter from the source, the induced voltage RMS will have a value at around $20 \mathrm{mV}$ from a certain sound intensity level. This signifies that to attain the maximum energy that can be produced; the device must be very close to the source as much as possible. 


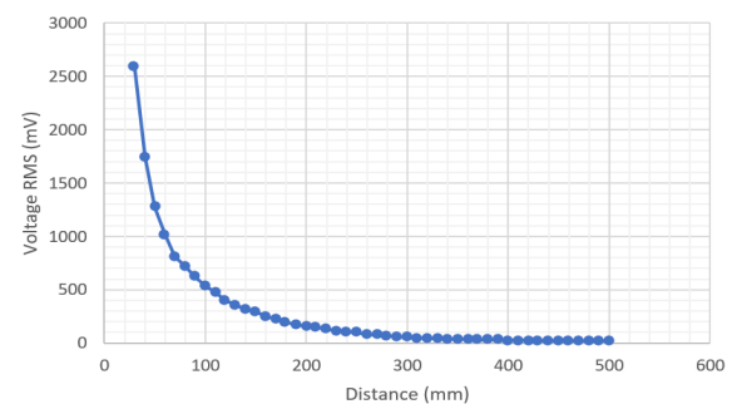

(a)

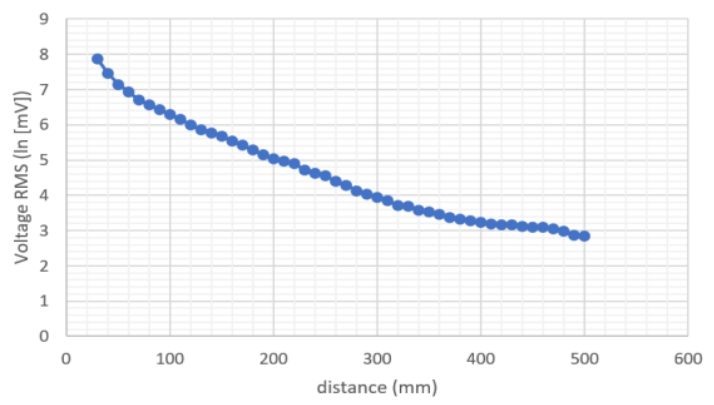

(b)

Figure 6. These figures are: (a) Voltage RMS vs distance plot and (b) voltage RMS vs distance logarithmic plot

Table 3. Regression statistics between the distance and voltage RMS (linear and logarithmic)

\begin{tabular}{llll}
\hline \multicolumn{4}{c}{ Regression statistics } \\
\multicolumn{2}{c}{ Linear regression model } & \multicolumn{2}{c}{ Logarithmic regression model } \\
\hline Multiple R & 0.697301597 & Multiple R & 0.976604462 \\
R Square & 0.486229518 & R Square & 0.953756275 \\
Standard Error & 356.4192274 & Standard Error & 0.307223412 \\
Observations & 48 & Observations & 48 \\
\hline
\end{tabular}

Table 4. Coefficients and significant value of variable $\mathrm{x}$ between the distance and voltage RMS (linear and logarithmic)

\begin{tabular}{lcclcc}
\hline & \multicolumn{4}{c}{ Regression statistics } \\
& Linear & \multicolumn{4}{c}{ Logarithmic regression model } \\
& Coefficient & Sig & & Coefficient & Sig \\
\hline Constant & 932.47987 & $7.72 \mathrm{E}-11^{* *}$ & Constant & 7.22448862 & $7.13 \mathrm{E}-50^{* *}$ \\
Distance (x) & -2.4501866 & $3.65 \mathrm{E}-08^{* *}$ & Distance (x) & -0.009859356 & $2.36 \mathrm{E}-32^{* *}$ \\
\hline ** Significant at 0.01 level Sig - significance (p-value) & & &
\end{tabular}

\subsection{Functionality assessment}

There were 4 data gathered during the experiment to test the functionality of the device. The device was $15 \mathrm{~mm}$ from the source. A capacitance that has a value of ten (10) millifarads was used for the circuit. The evaluation of the functionality of the device was done by a series of test. The device was tested three times per sound intensity level at five minutes per test. The researcher gathered a total of 12 data for four different sound intensity levels for a total time of one hour.

Table 5 shows the variety of sound intensity level that was used and the results was tallied after each test. At $80 \mathrm{~dB}$, it records a mean output voltage of $1.45 \mathrm{~V}$ and a stored energy of $10.51 \mathrm{~mJ}$. At $85 \mathrm{~dB}$, it records an average output voltage of $2.07 \mathrm{~V}$ and a stored energy of $21.36 \mathrm{~mJ}$. Then at $90 \mathrm{~dB}$, it records an average output voltage of $5.51 \mathrm{~V}$ and a stored energy of $151.62 \mathrm{~mJ}$. Lastly, an average output voltage of 8.63 $\mathrm{V}$ and a stored energy of $372.10 \mathrm{~mJ}$ was recorded for $95 \mathrm{~dB}$. This implies that it can be useful to the electronic components that needed small amount of power such as light-emitting diodes (LED) and transistors. The device was found to be functional since it was able to generate energy at all sound intensity levels.

Table 6 shows the corresponding results using completely randomized design (CRD). The test result is statistically significant with $\mathrm{p}$-value $<0.01$. As such, there is a significant increase in stored energy as the sound intensity level $(\mathrm{dB})$ of the source increases. This implies that the device was effective.

Table 5. Evaluation for the study in determining the functionality of the device based on stored energy at 10 $\mathrm{mF}$ and frequency of $80 \mathrm{~Hz}$

\begin{tabular}{|c|c|c|c|c|c|c|c|}
\hline \multirow{2}{*}{$\begin{array}{c}\text { Sound } \\
\text { Intensity } \\
\text { Level }(\mathrm{dB})\end{array}$} & \multirow{2}{*}{$\begin{array}{c}\text { Time of } \\
\text { Testing } \\
\text { (MIN) }\end{array}$} & \multicolumn{3}{|c|}{ Output Voltage (V) } & \multirow{2}{*}{$\begin{array}{l}\text { Average } \\
\text { (b) }\end{array}$} & \multirow{2}{*}{$\begin{array}{l}\text { Stored Energy } \\
(\mathrm{mJ})\end{array}$} & \multirow{2}{*}{$\begin{array}{l}\text { Functionality (Indicate } \\
\text { Whether 'Yes' Or 'No') }\end{array}$} \\
\hline & & $\mathrm{R} 1$ & $\mathrm{R} 2$ & R3 & & & \\
\hline 80 & 5 & 1.48 & 1.43 & 1.44 & 1.45 & 10.51 & YES \\
\hline 85 & 5 & 2.00 & 2.17 & 2.03 & 2.07 & 21.36 & YES \\
\hline 90 & 5 & 5.43 & 5.62 & 5.47 & 5.51 & 151.62 & YES \\
\hline 95 & 5 & 8.65 & 8.60 & 8.63 & 8.63 & 372.10 & YES \\
\hline
\end{tabular}




\begin{tabular}{lllllll}
\multicolumn{7}{c}{ Table 6. Result using completely randomized design } \\
\hline Source of Variation & SS & df & Ms & F & P-value & F Crit \\
\hline Between Groups & 99.70723 & 3 & 33.23574 & 6782.804422 & $5.87 \mathrm{E}-14$ & 4.066181 \\
Within Groups & 0.0392 & 8 & 0.0049 & & & \\
Total & 99.74643 & 11 & & & & \\
\hline
\end{tabular}

\section{CONCLUSION}

The objectives discussed in this study have been achieved as the results show that the developed device was fully functional in terms of getting the necessary data to be considered. It was concluded that there is an exponential increase and exponential decrease in the voltage RMS for every increase of sound intensity level with respect to the distance of the source. Furthermore, the device could generate enough energy to power up small electronics such as LEDs, transistors and resistors. To attain the maximum amount of energy, the device must be placed on the environment with high sound intensity level and must be adjacent to the source as much as possible when converting the movement and magnetism to electrical energy. It is recommended to evaluate the functionality of the device from many sources of sound especially in outside environment such as in streets and commercial buildings for considering it's practically in the society. Further research and study are encouraged for the improvement and advancement of the device.

\section{REFERENCES}

[1] H. M. Noh, "Acoustic harvesting using piezoelectric generator for railway environmental noise," Advances in Mechanical Engineering, vol. 10, no. 7, 2018, doi: 10.1177/1687814018785058.

[2] S. Deshpante, S. C. Sajjan, and H. Pujar, "System to Transform Sound Energy Into Electrical Energy," 2nd International Conference on Non-Conventional Energy: Nanotechnology \& Nanomaterials for Energy \& Environment (ICNNEE), 2019, pp. 1-8, doi: 10.2139/ssrn.3492946.

[3] D. C. S. Charan and B. Rajpathak, "Sound Energy Harvesting Methods," International Journal of Recent Technology and Engineering (IJRTE), vol. 8, no. 2S7, pp. 316-320, 2019, doi: 10.35940/ijrte.B1118.0782S719.

[4] D. Janssen and C. Janssen, Electromagnetic Induction, Techopedia, [Online]. Available: https://www.techopedia.com/definition/19997/electromagnetic-induction-circuits, 2019.

[5] D. Giancoli, Physics: Principles with Applications $5^{\text {th }}$ Edition, London, Britania Raya, UK: Pearson, 1998

[6] M. Garg, D. Gera, A. Bansal, and A. Kumar, "Generation of electrical energy from sound energy," 2015 International Conference on Signal Processing and Communication (ICSC), 2015, pp. 410-412, doi: 10.1109/ICSPCom.2015.7150687.

[7] M. Ovaiz, S. Rajkumar, K. Rajkumar, and D. Ramprasasd, "Generation of Electricity from Industrial Noise," International Research Journal of Engineering and Technology, vol. 3, no. 5, pp. 818-820, 2016.

[8] V. Kulkarni, S. Konda, D. Upadhyay, and B. Khandelwal, "Power Generation from Sound and Pressure," International Journal of Engineering Science and Computing, vol. 7, no. 5, pp. 11631-11633, 2017.

[9] P. Kulkarni, A. Tandsi, D. Bopanna, and N. Kamath, "Analysis of Conversion of Noise to Electrical Energy in a Stadium," International Journal of Industrial Electronics and Electrical Engineering, vol. 5, no. 9, pp. 39-42, 2017.

[10] S. Bhatnagar, "Converting Sound Energy to Electric," International Journal of Emerging Technology and Advanced Engineering, vol. 2, no. 10, pp. 267-270, 2012.

[11] V. Jaware, P. Gautam, R. Mar, A. Panday, and N. Sindhav, "Conversion of Noise Pollution Into Electrical Energy,"

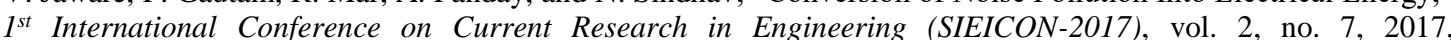
doi: 10.21090/ijaerd.ee001.

[12] B. Jo, D. Lee, J. Park, and C. Yeom., "An Experimental Investigation of Noise Energy Generation," International Conference on Chemical, Environment and Civil engineering (ICCECE'2012), 2012, pp. 158-161.

[13] H. Shao, et al., "Efficient conversion of sound noise into electric energy using electrospun polyacrylonitrile membranes," Nano Energy, vol. 75, 2020, doi: 10.1016/j.nanoen.2020.104956.

[14] N. Joshil, D. Kumar, D. Chhaudhary, and V. Mishra, "Study of conversion of Sound Energy into Electrical Energy," International Journal on Emerging Technologies, vol. 8, no. 1, pp. 101-103, 2017.

[15] A. Gupta, V. Goel, and V. Yadav, "Conversion of Sound to Electric Energy," International Journal of Scientific and Engineering Research, vol. 5, no. 1, pp. 2146-2149, 2014

[16] T. J. Seebeck, Magnetische Polarisation der Metalle und Erze durch Temperatur-Differenz in English Magnetic polarization of metals and minerals by temperature differences, Nabu Press, 1825

[17] A. Noxon. Absorption Retrieved from Acoustic Sciences Corporation, 2019. [Online]. Available: https://www.acousticsciences.com/hifi/

[18] Electricalvoice, Piezoelectric Transducer Advantages \& Applications, Nov. 2017. [Online]. Available: https://electricalvoice.com/piezoelectric-transducer-advantages-applications/

[19] L. H. Fang, S. I. S. Hassan, R. A. Rahim, M. Isa, and B. Ismail, "Exploring Piezoelectric for Sound Wave as Energy Harvester," Energy Procedia, vol. 105, pp. 459-466, 2017, doi: 10.1016/j.egypro.2017.03.341. 
[20] J. S. Rakin, "Study of Piezo-electric device for conversion of sound to electricity", University of Utah Oresto Symko, 2011. [Online]. Available: http://www.physics.utah.edu/ belz/phys3719/presentations/rankin.pdf

[21] G. Revathi and R. Ingitham, "Piezoelectric Energy Harvesting System in Mobiles with Keypad and Sound Vibrations," International Journal of Engineering Research \& Technology (IJERT), vol. 1, no. 4, pp. 1-4, 2012.

[22] S. Priya, and R. Myers, "Piezoelectric energy harvester", U. S. Patent application publication, 2008.

[23] Y. Farghaly, F. A. A. Hemeida, and S. Salah, "Noise utilization as an approach for reducing energy consumption in street lighting," PLOS ONE, vol. 14, no. 7, pp. 1-20, 2019, doi: 10.1371/journal.pone.0219373.

[24] J. Park, Y. Kim, and D. Kang, "Propagation Characteristics and Effects of Road Traffic Noise," Journal of Environmental Health Sciences, vol. 34, no. 4, pp. 311-315, 2008, doi: 10.5668/JEHS.2008.34.4.311.

[25] Y. Chen and C. C. Chang, "Lightning rabbit-an application of sound energy to produce more electricity," APEC Youth Scientist Journal, vol. 3, pp. 162-166, 2008.

\section{BIOGRAPHIES OF AUTHORS}
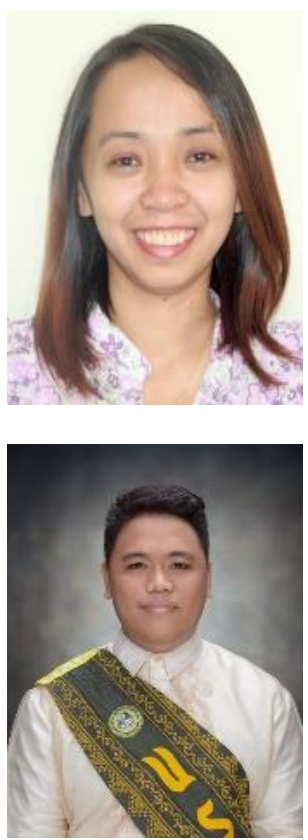

Maricel G. Dayaday is a faculty member and designated as Department Chairperson of Department of Electronics Engineering, College of Engineering and Information Technology, University of Southern Mindanao, Kabacan, North Cotabato. She is a licensed Electronics Engineer and an alumna of University of Southeastern Philippines (USeP), Davao City. She completed her Master of Engineering major in Electronics Engineering at University of Mindanao, Davao City.

Jordan-James S. Olivo was born in Sunrise Street, Kabacan, Cotabato on August 05, 1998. He graduated at the University of Southern Mindanao, Kabacan, North Cotabato with the degree of bachelor of Science in Electronics Engineering as Magna Cum Laude. 